\title{
Comparison of in Clinic-Based Fecal Microbiome Collection Techniques for Increase in Study Participation and Utilization of Microbiome Analysis
}

\author{
Benjamin D. Besasie1, Dimpy P. Shah², Robin J. Leach¹, Michael A. Liss ${ }^{1}$ \\ ${ }^{1}$ Department of Urology, UT Health San Antonio, San Antonio, TX, USA \\ ${ }^{2}$ Department of Epidemiology and Biostatistics, UT Health San Antonio, San Antonio, TX, USA \\ Email: ben.besasie@gmail.com
}

How to cite this paper: Besasie, B.D., Shah, D.P., Leach, R.J. and Liss, M.A. (2019) Comparison of in Clinic-Based Fecal Microbiome Collection Techniques for Increase in Study Participation and Utilization of Microbiome Analysis. Open Journal of Urology, 9, 51-61.

https://doi.org/10.4236/oju.2019.93006

Received: January 6, 2019

Accepted: March 5, 2019

Published: March 8, 2019

Copyright $\odot 2019$ by author(s) and Scientific Research Publishing Inc. This work is licensed under the Creative Commons Attribution International License (CC BY 4.0).

http://creativecommons.org/licenses/by/4.0/

c) (i) Open Access

\begin{abstract}
We compared the collection techniques of fecal specimens for DNA extraction and fecal microbiome analysis by utilizing the glove from a standard-of-care digital rectal exam (DRE) and the rectal swab from a pre-prostate biopsy bacterial rectal culture collected in clinical care settings. DNA yield from the swab technique compared to the glove technique yielded similar amounts of DNA (18.1 vs. $13.1 \mathrm{ng} / \mu \mathrm{L}, \mathrm{p}=0.06$ ), slightly favoring the swab technique. However, utilizing DNA yield cutoffs of $15 \mathrm{ng} / \mu \mathrm{L}$ (37\% vs. $29 \%, \mathrm{p}=0.18)$ and $30 \mathrm{ng} / \mu \mathrm{L}(15 \%$ and $9 \%, \mathrm{p}=0.16)$, we identified no differences in yield between the swab versus glove technique, respectively. Absorbance values for overall DNA quality were significantly different in favor of the glove technique (mean 1.6 vs. $2.0, \mathrm{p}<0.001$ ). Using an absorbance value of 1.5 as an indication of DNA quality, only $26 \%$ (19/91) met the cutoff value using the swab group compared to $47.3 \%$ (53/112) if the glove technique was used ( $\mathrm{p}<0.001$ ). Similar results occurred for the RNA quality with an absorbance value cutoff of 2.0 ( $2.2 \%$ vs. $30.4 \%, \mathrm{p}<0.001)$. To increase sampling feasibility and improve population sampling, gloves used from a DRE may be utilized as a consistent and efficient fecal DNA collection technique for fecal microbiome analysis. DNA yield and quality from the glove technique are comparable to-if not better than-rectal swab collection.
\end{abstract}

\section{Keywords}

Fecal Microbiome, Stool, Collection Technique, Swab, Glove, Urology,

Digital Rectal Exam, 16S rRNA Gene Sequencing 


\section{Introduction}

Advances in microbiome analysis have led to new approaches and investigation into microbiological influence on cancer pathogenesis. In order to expand microbiome research, collection of samples should be incorporated into clinical care with easy attainment. The intestinal microbiome may play a potential role in the pathogenesis of many types of cancer, therefore leading to potential modifiable biomarkers to be utilized along with cancer-screening programs [1] [2] [3] [4]. Additional studies have shown that intestinal microbiota is essential for cancer immunotherapy [3]. With advances in next-generation sequencing (NGS), the microbiome is a relatively new field with enormous implications to our health [5]. While the microbiome has largely been investigated in gastrointestinal cancers, microbiome research is rapidly expanding to non-gastrointestinal disease due to its implications on circulating metabolites [2] [5] [6] [7].

Unfortunately, there have been limited reports investigating the effectiveness of fecal collection techniques that would have implications for future clinical trials. Currently, collection of stool is the gold standard for fecal microbiome studies [8] [9] [10]. However, in clinical trials of colorectal cancer, only $60 \%$ of patients, and less so among men, participated or returned their at-home collected stool specimens, leading to a collection bias [11]. Capturing samples during an in-clinic visit would save time and improve the number of subjects participating in the study while reducing collection biases. Studies have found that rectal swab versus stool collection samples yield similar results [12] [13] [14].

Herein, we test the collection of fecal specimen using a double-gloved technique during a standard-of-care digital rectal exam (DRE) for prostate examination. We hypothesize that DRE glove collection will yield similar DNA isolation for microbiome analysis when compared to a retrospective study that used a rectal swab collection technique for fecal microbiome analysis.

\section{Materials and Methods}

\subsection{Study Population}

After approval by the Institutional Review Board at UT Health San Antonio, we performed a pilot study evaluating the fecal microbiome collection techniques of fecal DRE glove collection and fecal rectal swab collection. Subjects for this study were selected via a convenience sampling method and approached at their already scheduled standard-of-care appointment or procedure. From an on-going NIH clinical cohort study as part of the San Antonio Biomarkers of Risk for Prostate Cancer (SABOR), DRE gloves were collected from 112 men at their annual screening appointment. Rectal swabs were collected from 91 men at the South Texas Veterans Health Care System for their pre-prostate biopsy bacterial rectal culture as a retrospective comparator group. Subject demographics can be found in Table 1.

The criteria for inclusion of DRE glove collection were as follows: Men scheduled for an annual standard-of-care prostate DRE as a part of the San Antonio 
Biomarkers of Risk for Prostate Cancer (SABOR) study.

The criteria for inclusion of rectal swab collection were as follows: Men scheduled for a standard-of-care prostate biopsy with a bacterial rectal culture swab prior to biopsy at the South Texas Veterans Health Care System.

\subsection{Sample Collection}

\subsubsection{DRE Glove Collection}

The double-glove technique involved the urology provider wearing two non-sterile latex gloves on the hand used for the DRE as seen in Figure 1A. DRE was performed per standard-of-care protocol with an individual packet of sterile lubricating jelly. Once the examination was finished, the provider removed outer glove by pulling at the base opening with opposite hand. The outer glove was removed with the inner surface turned outward, in an effort to completely turn the index finger inside out to avoid contamination and loss of fecal matter as seen in Figure 1B. This was completed by rolling the index finger on the thumb of the same hand as seen in Figure 1C. The outer glove, with the index finger completely inside out, was placed on an unused pad as seen in Figure 1D. Sterilized surgical scissors and forceps were used to cut off the index finger of the glove at the knuckle (metacarpophalangeal joint) as seen in Figure 1E. With the forceps, the finger from the DRE glove was placed in a $5 \mathrm{~mL}$ conical tube containing $1 \mathrm{~mL}$ of phosphate-buffered saline (PBS). Sterilization solution for the instruments contained $90 \mathrm{~mL} 95 \%$ ethanol and $10 \mathrm{~mL} 10 \%$ bleach. The glove specimen was then stored at $4^{\circ} \mathrm{C}$ during transport to the laboratory. After delivery to the lab, the glove tip was removed from collection tube and reinverted using a P1000 pipette tip or stick portion of a swab. The glove tip was placed in a $2.0 \mathrm{~mL}$ microfuge tube. PBS solution from collection tube was pipetted and used to rinse the glove tip to remove all collected fecal material into the $2.0 \mathrm{~mL} \mathrm{mi}$ crofuge tube. The glove tip was then discarded. PBS material was stored at $-20^{\circ} \mathrm{C}$ until DNA isolation was performed.

Table 1. Subject demographics.

\begin{tabular}{lccc}
\hline \multicolumn{1}{c}{ Demographic } & Glove $(\mathbf{n}=\mathbf{1 1 2})$ & Swab $(\mathbf{n}=91)$ & P value \\
\hline Age & $67(61-73)$ & $66(60-69)$ & 0.05 \\
PSA & $1.3(0.6-2.6)$ & $6.5(4.6-9.6)$ & 0.13 \\
BMI & $26.9(24.4-31.3)$ & $29.2(26.6-34.1)$ & 0.01 \\
Race/Ethnicity & & & $<0.01$ \\
White & $67(60.4 \%)$ & $47(57.3 \%)$ & $<(32.9 \%)$ \\
$\quad$ Black & $12(10.8 \%)$ & $8(9.8 \%)$ & $<0.01$ \\
Hispanic & $32(28.8 \%)$ & $32(35.2 \%)$ & $<0.01$ \\
Diabetes & $17(15.2 \%)$ & $4(4.4 \%)$ & $<0.01$ \\
Antibiotic in the last 90 days & $0(0 \%)$ & $1.05(0.85-1.33)$ & $<0.01$ \\
LogDNA (DNA Yield) & $0.92(0.63-1.21)$ & $1.63(1.53-1.76)$ & \\
260/280 (RNA Quality) & $1.76(1.59-2.07)$ & &
\end{tabular}



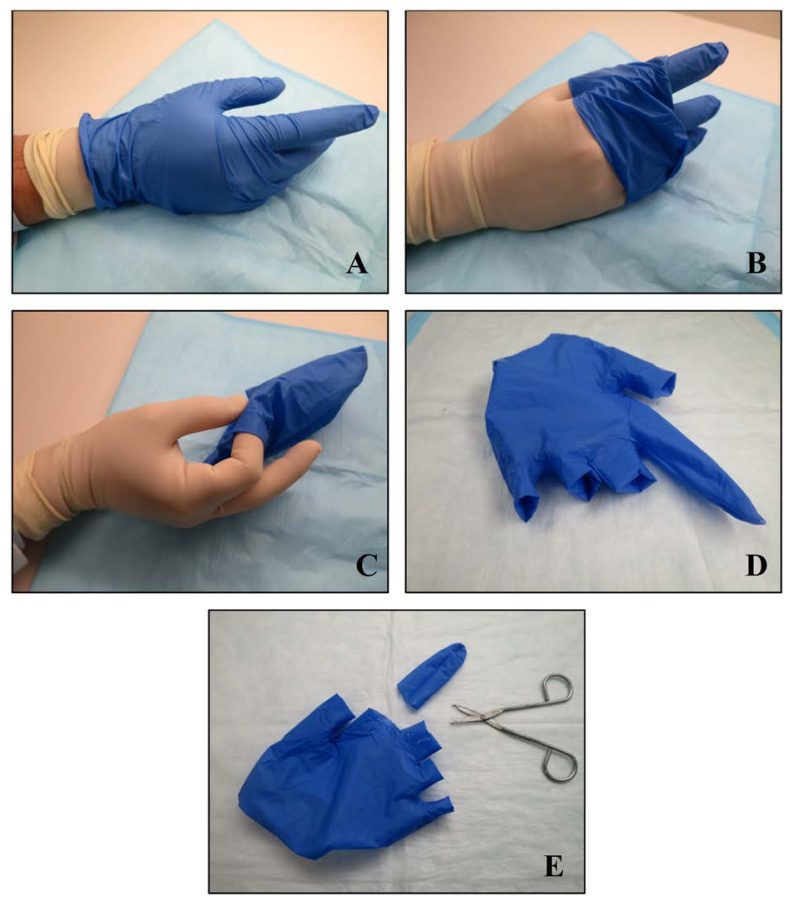

Figure 1. Photographs demonstrating digital rectal exam (DRE) glove removal technique for collection of fecal specimens. A: Provider wearing two non-sterile latex gloves on the hand used for the DRE, demonstrating the double-glove technique; B: Outer glove removed with the inner surface turned outward to avoid contamination or loss of fecal matter; C: Provider rolling the index finger of the outside glove on the thumb of the same hand, in an effort to completely turn the index finger inside out; D: Outside glove and index finger completely inside out placed on an unused pad; E: Index finger from inside out, outside glove cut at the knuckle (metacarpophalangeal joint), with sterilized surgical scissors.

\subsubsection{Rectal Swab Collection}

The rectal swab technique involved the urology provider placing the swab on the gloved finger used for a standard-of-care DRE with an individual packet of sterile lubricating jelly. Once examination was finished, the rectal swab was placed in a 15 $\mathrm{mL}$ sterile centrifuge tube containing $1 \mathrm{~mL}$ of phosphate-buffered saline (PBS). The swab specimen was then stored at $4^{\circ} \mathrm{C}$ during transport to the laboratory. After delivery to the lab, fecal swab was removed from collection tube, and the PBS solution was pipetted into a $2.0 \mathrm{~mL}$ microfuge tube. The cotton portion of the swab was scraped into the microfuge tube using a sterilized scalpel blade. Swab and PBS material were then stored at $-20^{\circ} \mathrm{C}$ until DNA isolation was performed.

\subsection{DNA Isolation and Quantification}

DNA was isolated from fecal samples on a DRE glove or rectal swab using our standard operating procedure as seen in Appendix. Purification of genomic DNA from these respective fecal samples was performed using the QIAamp Fast DNA Stool Mini Kit produced by the company QIAGEN. DNA quantification from fecal samples was calculated using the Thermo Scientific ${ }^{\mathrm{Tm}}$ NanoDrop ${ }^{\mathrm{m}}$ to measure the absorbance and calculate the concentration of nucleic acids (260 
$\mathrm{nm})$ and purified proteins $(280 \mathrm{~nm})$.

\subsection{Statistical Analysis}

After DNA/RNA isolation for future 16S rRNA gene sequencing microbiome analysis, we analyzed the yield from extraction. The outcome utilized was yield and quality. DNA yield is simply the amount of DNA isolated while quality of the DNA and RNA was determined using specific absorbance values. For yield, we utilized the $\mathrm{ng} / \mu \mathrm{L}$ from the NanoDrop output and compared the techniques utilizing the T-Test. For nucleic acid quality, we utilized the ratio of $260 \mathrm{~nm}$ absorbance maximum to the absorbance at $280 \mathrm{~nm}$ as a measure of purity in both DNA and RNA extractions. We utilized a cutoff of ratio 1.8 for DNA and 2.0 for RNA and applied the chi-square test to determine the proportion of samples that would meet this threshold by collection technique.

\section{Results}

We identified 91 subjects who had rectal swabs for fecal microbiome collection compared to 112 using the glove technique. DNA yield from the swab technique compared to the glove technique yielded similar amounts of DNA (18.1 vs. 13.1 $\mathrm{ng} / \mu \mathrm{L}, \mathrm{p}=0.06)$ as seen in Figure 2, slightly favoring the swab technique. Utilizing DNA yield cutoffs of $15 \mathrm{ng} / \mu \mathrm{L}(37 \%$ vs. $29 \%, \mathrm{p}=0.18)$ and $30 \mathrm{ng} / \mu \mathrm{L}(15 \%$ and $9 \%, p=0.16$ ), we identified no differences between the swab versus glove technique, respectively. Overall 260/280 nm absorbance for overall quality was significantly different in favor of the glove technique (mean 1.6 vs. 2.0, p < 0.001 ) as seen in Figure 3. Using an absorbance value of 1.5 as an indication of DNA quality, only $26 \%$ (19/91) met the cut off value using the swab group compared to $47.3 \%(53 / 112)$ if the glove technique was used ( $p<0.001)$. Similar results occurred for the RNA quality with a 260/280 absorbance value cutoff of 2.0 ( $2.2 \%$ vs. $30.4 \%, p<0.001)$.

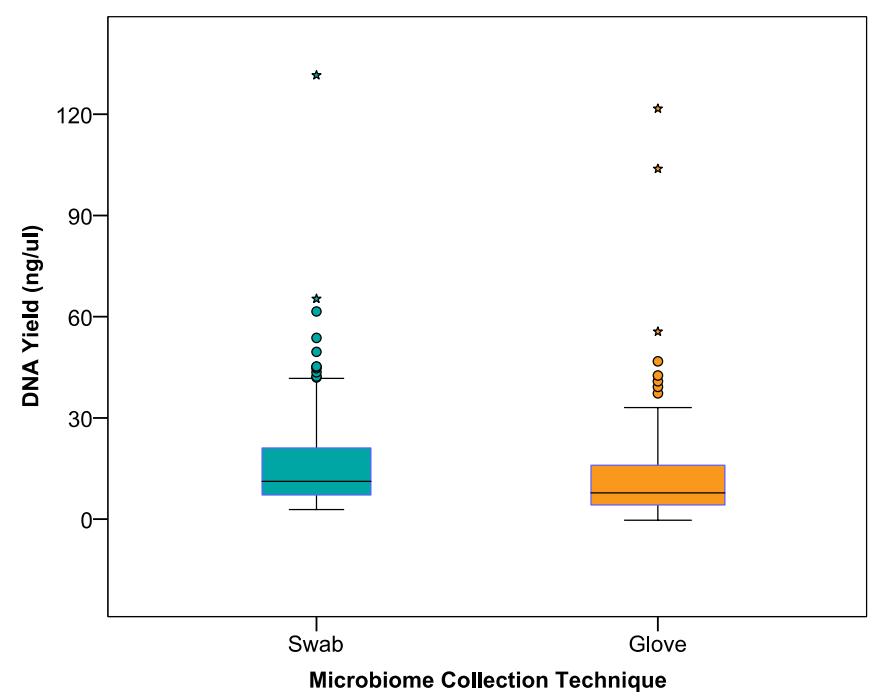

Figure 2. Comparison of rectal swab versus DRE glove collection DNA yield (ng/ $\mu \mathrm{L})$. 


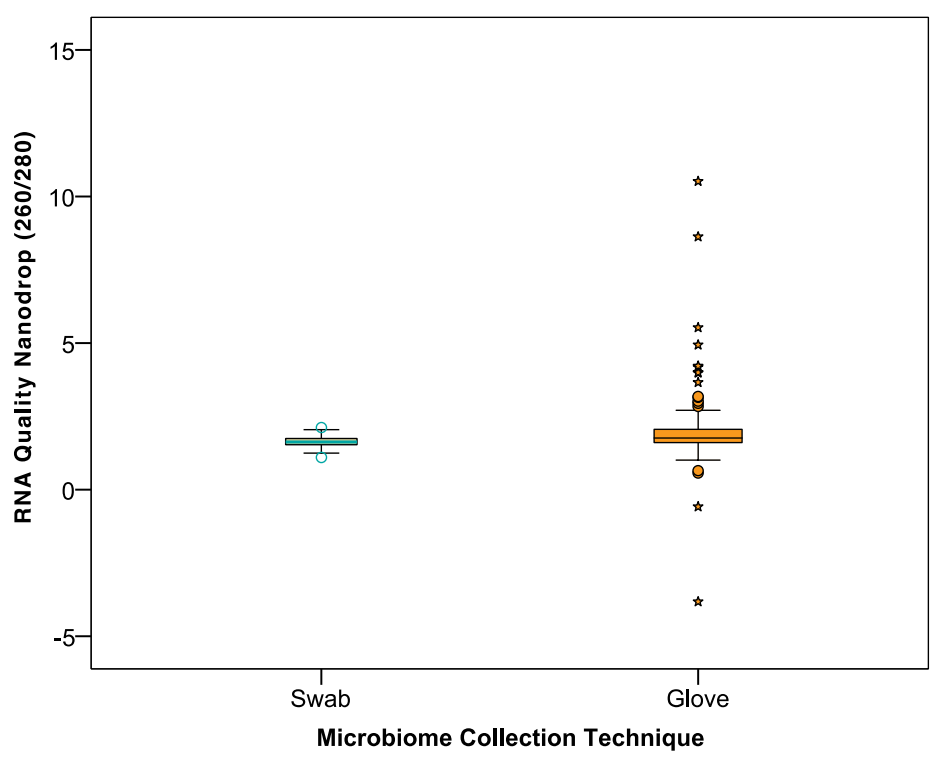

Figure 3. Comparison of rectal swab versus DRE glove collection RNA quality absorbance values $(260 / 280 \mathrm{~nm})$.

\section{Discussion}

DNA collection for fecal microbiome testing in the context of standard clinical care is feasible and convenient for clinicians. Utilization of a two-glove technique at the time of rectal examination had superior DNA quality, despite less DNA yield on average than the rectal swab technique. The glove technique used the glove from a standard-of-care digital rectal exam (DRE) when screening for prostate cancer, which contains fecal residue. This technique also could be used at the time of fecal occult testing for colon cancer. One study noted the fecal occult cards could also be used for DNA analysis but can be cumbersome to remove DNA from the cards in the research laboratory [15]. The swab technique collected the swab used from a standard-of-care pre-prostate biopsy bacterial rectal culture that is typically sent to microbiology labs to examine for fluoroquinolone-resistant E. coli for pre-prostate biopsy targeted prophylaxis. Both techniques utilize standard-of-care techniques. Specifically, in prostate cancer, men undergo a DRE in order to palpate the prostate. It is at this time a rectal swab could be obtained. However, by using a rectal swab at time of DRE, this may add extra discomfort to the patient if done separately from a DRE or may detract from the effectiveness of the exam from the provider's standpoint. To our best knowledge, no studies regarding the fecal microbiome collection techniques have been performed in the clinical urology setting.

Analyzing the microbiome through next-generation sequencing (NGS) requires adequate and quality DNA to perform the testing. One of the two main approaches for investigating an individual's microbiota uses 16S rRNA genes, as the most common marker [16] [17]. According to our institution's Nucleic Acids Core Facility, 10 - $20 \mathrm{ng} / \mu \mathrm{L}$ of high-quality DNA is required for PCR amplification of the hypervariable regions of the $16 \mathrm{~S}$ rRNA genes [18]. According to 
other university Genomic Cores, a minimum of $1 \mathrm{ng} / \mu \mathrm{L}$ of DNA is required [19]. Therefore, the amounts of purified DNA obtained utilizing the glove technique fall within the necessary range for $16 \mathrm{~S}$ rRNA gene sequencing.

Our results show that DNA yield and quality from the glove technique are well-suited for consistent and efficient routine sampling for analysis of the fecal microbiome. This could be due to the fact that there is more likely to be actual stool on the glove instead of attempting to extract it from a rectal swab. Additionally, the stool, and thus the DNA, may come off the glove more purely than the swab. The swabs used in the rectal swab collection method were standard cotton swabs; improved collection may be obtained from using more brush-like swabs so that fecal material does not penetrate the cotton, thus becoming difficult to extract. Previous studies have already noted a similar DNA yield and microbiome analysis between stool and rectal swabs [12] [14]; therefore, we were focused on determining if obtaining DNA from the gloved finger during a standard-of-care DRE was possible or not largely different in order to identify a new technique that does not have the same difficulties as stool sample collection. Obtaining actual stool samples can be challenging due to fecal incontinence, level of embarrassment from patients, inconsistency of sample collection by individuals themselves, and increased collection cost [8] [9] [13] [14] [20] [21].

With this information, we will be able to collect a larger number of fecal samples in the urological setting to study the effect the fecal microbiome has on prostate cancer [1] [2]. With the ability to study the fecal microbiome by using the glove technique, we will also be able to curb any patient-level collection factors. Glove collection after a DRE is relatively simple to collect, requires no patient preparation, and can be transported easily from the clinic to the laboratory, when compared to stool collection, which is more complicated to collect and subject dependent. In a urology clinic, when patients are seen for their standard-of-care annual prostate exam, we will no longer need to subject the patient to any additional screening procedures, such as a rectal swab, nor incur additional materials costs, if we were to use the glove technique.

There are some limitations to our study. While we collected fecal samples from gloves and swabs on different individuals, we did not compare each technique on the same individual. Additionally, as we did not perform 16S rRNA gene sequencing on the isolated DNA samples, we are unable to evaluate if each collection technique contained the same microbiota per respective individual. While DNA yield from glove to swab may be comparable, according to one study, there may be distinct differences in the microbiome composition between swab and stool samples, and possibly in our case, DRE glove samples [12]. Furthermore, sensitivity and specificity of the technique will require us to perform these methods compared to each other as compared to a stool sample which would be the gold standard. The goal of this manuscript is to establish a new collection technique at its inception. To address these limitations, our next study will compare different fecal collection techniques (glove, swab, and stool samples) on the same individual to obtain sensitivity and specificity while evaluating 
DNA yield and purity and microbiome analysis through NGS. Our current study is the first to establish that the glove technique is valid and can be utilized for fecal sample collection to be used for microbiome analysis.

\section{Conclusion}

In summary, fecal microbiome studies for non-gastrointestinal patients undergoing a rectal/prostate exam may be able to utilize the glove used for a digital rectal exam (DRE) as a fecal collection method for DNA sequencing, which may increase sampling feasibility and improve population sampling without altering results.

\section{Ethics Approval and Consent to Participate}

The study was approved by the office of the Institutional Review Board at UT Health San Antonio and the South Texas Veterans Health Care System. All specimens from the swab collection technique, performed as standard of care, were collected as discarded material through a tissue repository (HSC20050234H) and distributed to an ongoing microbiological study (HSC20170754N). The glove collection technique cohort was consented prior to collection (HSC20000030H).

\section{Availability of Data and Material}

The datasets used and/or analyzed during the current study are available from the corresponding author on reasonable request.

\section{Funding}

The research was supported by a generous gift from the Los Padres Foundation based in San Antonio, Texas.

\section{Acknowledgements}

The authors thank the research staff, investigators, and subjects who have contributed to the San Antonio Biomarkers of Risk for Prostate Cancer (SABOR) study and the laboratory staff in the Cell Systems \& Anatomy Department at UT Health San Antonio.

\section{Conflicts of Interest}

The authors declare no conflicts of interest regarding the publication of this paper.

\section{References}

[1] Golombos, D.M., Ayangbesan, A., O’Malley, P., Lewicki, P., Barlow, L., Barbieri, C.E., Chan, C., DuLong, C., Abu-Ali, G., Huttenhower, C. and Scherr, D.S. (2018) The Role of Gut Microbiome in the Pathogenesis of Prostate Cancer: A Prospective, Pilot Study. Urology, 111, 122-128. https://doi.org/10.1016/j.urology.2017.08.039

[2] Amirian, E.S., Petrosino, J.F., Ajami, N.J., Liu, Y., Mims, M.P. and Scheurer, M.E. 
(2013) Potential Role of Gastrointestinal Microbiota Composition in Prostate Cancer Risk. Infectious Agents and Cancer, 8, 42. https://doi.org/10.1186/1750-9378-8-42

[3] Sfanos, K.S., Yegnasubramanian, S., Nelson, W.G. and De Marzo, A.M. (2018) The Inflammatory Microenvironment and Microbiome in Prostate Cancer Development. Nature Reviews Urology, 15, 11-24. https://doi.org/10.1038/nrurol.2017.167

[4] Shrestha, E., White, J.R., Yu, S.H., Kulac, I., Ertunc, O., De Marzo, A.M., Yegnasubramanian, S., Mangold, L.A., Partin, A.W. and Sfanos, K.S. (2018) Profiling the Urinary Microbiome in Men with Positive versus Negative Biopsies for Prostate Cancer. Journal of Urology, 199, 161-171. https://doi.org/10.1016/j.juro.2017.08.001

[5] Feng, Q., Chen, W.D. and Wang, Y.D. (2018) Gut Microbiota: An Integral Moderator in Health and Disease. Frontiers in Microbiology, 9, 151.

https://doi.org/10.3389/fmicb.2018.00151

[6] Marchesi, J.R., Adams, D.H., Fava, F., Hermes, G.D., Hirschfield, G.M., Hold, G., Quraishi, M.N., Kinross, J., Smidt, H., Tuohy, K.M., et al. (2016) The Gut Microbiota and Host Health: A New Clinical Frontier. Gut, 65, 330-339. https://doi.org/10.1136/gutjnl-2015-309990

[7] Brennan, C.A. and Garrett, W.S. (2016) Gut Microbiota, Inflammation, and Colorectal Cancer. Annual Review of Microbiology, 70, 395-411. https://doi.org/10.1146/annurev-micro-102215-095513

[8] Wu, W.K., Chen, C.C., Panyod, S., Chen, R.A., Wu, M.S., Sheen, L.Y. and Chang, S.C. (2018) Optimization of Fecal Sample Processing for Microbiome Study-The Journey from Bathroom to Bench. Journal of the Formosan Medical Association.

[9] Han, M., Hao, L., Lin, Y., Li, F., Wang, J., Yang, H., Xiao, L., Kristiansen, K., Jia, H. and Li, J. (2018) A Novel Affordable Reagent for Room Temperature Storage and Transport of Fecal Samples for Metagenomic Analyses. Microbiome, 6, 43. https://doi.org/10.1186/s40168-018-0429-0

[10] Human Microbiome Project C (2012) Structure, Function and Diversity of the Healthy Human Microbiome. Nature, 486, 207-214. https://doi.org/10.1038/nature11234

[11] von Euler-Chelpin, M., Brasso, K. and Lynge, E. (2010) Determinants of Participation in Colorectal Cancer Screening with Faecal Occult Blood Testing. Journal of Public Health (Oxford), 32, 395-405. https://doi.org/10.1093/pubmed/fdp115

[12] Jones, R.B., Zhu, X., Moan, E., Murff, H.J., Ness, R.M., Seidner, D.L., Sun, S., Yu, C., Dai, Q., Fodor, A.A., et al. (2018) Inter-Niche and Inter-Individual Variation in Gut Microbial Community Assessment Using Stool, Rectal Swab, and Mucosal Samples. Scientific Reports, 8, 4139. https://doi.org/10.1038/s41598-018-22408-4

[13] Budding, A.E., Grasman, M.E., Eck, A., Bogaards, J.A., Vandenbroucke-Grauls, C.M., van Bodegraven, A.A. and Savelkoul, P.H. (2014) Rectal Swabs for Analysis of the Intestinal Microbiota. PLoS ONE, 9, e101344. https://doi.org/10.1371/journal.pone.0101344

[14] Bassis, C.M., Moore, N.M., Lolans, K., Seekatz, A.M., Weinstein, R.A., Young, V.B., Hayden, M.K. and Program, C.D.C.P.E. (2017) Comparison of Stool versus Rectal swab Samples and Storage Conditions on Bacterial Community Profiles. BMC Microbiology, 17, 78. https://doi.org/10.1186/s12866-017-0983-9

[15] Vogtmann, E., Chen, J., Kibriya, M.G., Chen, Y., Islam, T., Eunes, M., Ahmed, A., Naher, J., Rahman, A., Amir, A., et al. (2017) Comparison of Fecal Collection Methods for Microbiota Studies in Bangladesh. Applied and Environmental Microbiology, 83, e00361-17. https://doi.org/10.1128/AEM.00361-17 
[16] Janda, J.M. and Abbott, S.L. (2007) 16S rRNA Gene Sequencing for Bacterial Identification in the Diagnostic Laboratory: Pluses, Perils, and Pitfalls. Journal of Clinical Microbiology, 45, 2761-2764. https://doi.org/10.1128/JCM.01228-07

[17] Jovel, J., Patterson, J., Wang, W., Hotte, N., O’Keefe, S., Mitchel, T., Perry, T., Kao, D., Mason, A.L., Madsen, K.L. and Wong, G.K. (2016) Characterization of the Gut Microbiome Using 16S or Shotgun Metagenomics. Frontiers in Microbiology, 7, 459. https://doi.org/10.3389/fmicb.2016.00459

[18] In University of Texas Health Science Center, Nucleic Acid Sequencing Core.

[19] In Michigan State University Genomic Core.

[20] Jones, R.M., Devers, K.J., Kuzel, A.J. and Woolf, S.H. (2010) Patient-Reported Barriers to Colorectal Cancer Screening: A Mixed-Methods Analysis. American Journal of Preventive Medicine, 38, 508-516. https://doi.org/10.1016/j.amepre.2010.01.021

[21] Coronado, G.D., Schneider, J.L., Sanchez, J.J., Petrik, A.F. and Green, B. (2015) Reasons for Non-Response to a Direct-Mailed FIT Kit Program: Lessons Learned from a Pragmatic Colorectal-Cancer Screening Study in a Federally Sponsored Health Center. Translational Behavioral Medicine, 5, 60-67.

https://doi.org/10.1007/s13142-014-0276-x 


\section{Appendix}

UT Health San Antonio Department of Urology Division of Research laboratory standard operating procedure for DNA extraction and storage from fecal speci-

mens.

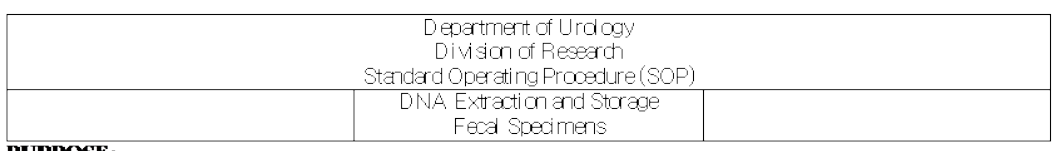

\section{PURPOSE:}

The purpose of thi SSOP is to out ine the process for extracting and storing DNA from fecd sampl es for mionobiome andys sthrough 165 rRNA gene sequencing

\section{RESPONSIBIITYY:}

Exeation of thi sSOP: All appropriately traned laboratory personnel

\section{PROCEDURES:}

1. Feca sample obtained by urdogy provider.

a. If SWAB: Remove feca swab from the odlecti on tube oontaining PBS. Pipet the PBS into a 2.0 $\mathrm{mL}$ mi arofuge tube. U se a sal pel blade to sorape the ootton porti on of the swab into the tube. Discard the stick portion of the swab.

b. If GLOV E, remove gl ove portian from tube and use the stick porticn of a swab ( $a$ a P1000 tip) to reinvert the fingertip. U se the PBS from the tube, or additiona PBS, as needed, to rinse the

fingertip and remove al oollected materia into a $2 \mathrm{~mL}$ mi croositrifuge tube. Discard the gl ove tip.

2. Spin the mi crooentrifuge tube at maxi mum speod (approxi mately $16000 \times \mathrm{g}$ ) for 5 mi nutes. Remove any liquid in exoess of $200 \mathrm{\mu L}$. Swab materia should be left in the tube. Store the PBS (and swab materia, if present) at $-20^{\circ} \mathrm{C}$ until DNA extraction is petormed.

3. When there are enough sampl es for extraction (at least 12), al ow the sampl es to thaw on ioe.

4. If volumes exoeed $200 \mathrm{\mu L}$ liquid, soin sampl esin ami crocentrifuge for 5 minutes at maximum speod (approxmately $16000 \times g$ ).

5. Carefully remove all but $200 \mathrm{HL}$ of supernatant, taking care not to di sturb any vis ble fecal partice pellet. Leave swab materia, if present.

6. Resuspend fecd partid es/swab materia in remaining $200 \mathrm{\mu L}$ and then extract using the QI AGEN Ql Aamp(B) Fast DNA Stod Miri Kit (50), catalog number 51604. U se the 'pathogen detection' detals, as falows

7. Add $1 \mathrm{~mL}$ I nhibitEX Buffer to each sample V ortex oantinuous y for 1 minute or until the stoo sampleis thoroughly homogenized.

8. Heat the suspens on at $70^{\circ} \mathrm{C}\left(90^{\circ} \mathrm{C}\right.$ for difficul tolyse bacteria) for 5 minutes and then vortex for 15 seconds

9. Centrifuge at maximum speed (aporoximately $16000 \times \mathrm{g}$ ) for 1 minute to pell et stod partides

10. Pipet $200 \mathrm{\mu L}$ of the supernatant into a new $1.5 \mathrm{~mL}$ tube oontaining $15 \mu \mathrm{L}$ of Proteinase $\mathrm{K}$. D o not transer swab materia

11. A.dd $200 \mu \mathrm{L}$ of Buffer AL and vortex for 15 seoonds.

12. Incubate at $70^{\circ} \mathrm{C}$ for 10 minutes.

13. Add $200 \mathrm{HL}$ of $100 \% \mathrm{EtOH}$ and vortex

14. Apply $600 \mathrm{HL}$ to the QI Aamp spin column. Centrifuge for 1 mi inute at $16000 \times \mathrm{g}$. Discard fil trate from the od ection tube and repeat if neossary until al the lysate has bean loaded on the od umn. Discard the fl owthrough.

15. Add $500 \mathrm{HL}$ of Buffer AW 1 to the ool umn and centrifuge for 1 minute at $16000 \times \mathrm{g}$. Discard fl ow-through.

16. Add $500 \mu \mathrm{L}$ of Buffer AW 2 to the oolumn and oentrifuge for 3 minutes at $16000 \times \mathrm{g}$. Place soin od umn into a new od lection tube.

17. Add $200 \mu \mathrm{L}$ (lessfor more conoentrated D NA) of nud ease free $\mathrm{H}_{2} \mathrm{O}$ (not buffer ATE) di rectly to the soin od umn membrane. Inoubate for 1 minute at room temperature. Centrifuge for 1 minute at $16000 \times \mathrm{g}$ to eluteDNA.

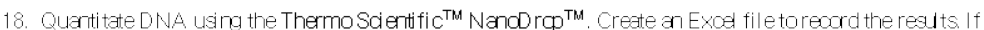
yield is expected to be low, speed vac sampl es to conoentrate them before determining oonoentration. Otherwise, l ow yield samples may be speed vac'd after quartitation, resuspended (if necessary) in alow volume of water, and requanti tated by NanoD rop ${ }^{\mathrm{TM}}$. 